\title{
Conceitos de Affordance e de Agência na Relação Professor- Materiais Curriculares em Educação Matemática
}

\author{
Concepts of Affordance and Agency in Teacher-Curriculum Materials \\ Relationship in Mathematics Education
}

\author{
Gilberto Januario* \\ Ana Lúcia Manrique ${ }^{* *}$ \\ Célia Maria Carolino Pires ${ }^{* * *}$
}

\begin{abstract}
Resumo
Estudos sobre a relação professor-materiais curriculares apresentam diferentes elementos que influenciam essa interação, como affordance e agência. Neste artigo, o nosso propósito é explorar esses conceitos e discutir seus significados na relação que professores estabelecem com materiais curriculares em Educação Matemática. Para proceder à conceitualização, realizamos busca de artigos e livros, seguida de uma triagem e posterior análise e exploração dos conceitos na perspectiva do estudo bibliográfico. Quanto à discussão de significados, tomamos o relatório de uma pesquisa como objeto de estudo para realizar a análise, na perspectiva da metanálise, de aspectos que ilustram como esses conceitos estão associados a essa relação. O quadro teórico reporta-se a autores que discutem a teoria da affordance e a teorizações sobre estruturação, especificamente sobre agência. A análise dos dados mostra que conhecimentos, crenças e valores dos professores influenciam na captação de informações dos materiais curriculares, levando-os a perceber affordances, situar a agência em si próprios e nos materiais e provocar o deslocamento de poder entre ambos os agentes. Mostra, ainda, que affordances e agência podem ser competências coletivas propiciadas pelo intercâmbio entre professores e seus pares.
\end{abstract}

Palavras-chave: Educação Matemática. Relação Professor-Materiais Curriculares. Currículos de Matemática. Affordance. Agência.

\begin{abstract}
Studies on the relationship between teacher-curriculum materials present different elements that influence this interaction, such as affordance and agency. In this article, our purpose is to explore these concepts and discuss their meanings in the relationship that teachers establish with curriculum materials in Mathematics Education. To proceed with the conceptualization, we researched for articles and books, followed by a screening and subsequent analysis and exploration of the concepts in the bibliographic study's perspective. Regarding the discussion of meanings, we chose a research as object of study to carry out the analysis, in the meta-analysis perspective, of aspects that illustrate how these concepts are associated with this relationship. The theoretical framework refers to authors who discuss affordance theory and theorizing about structuring, specifically agency.

\footnotetext{
* Doutor em Educação Matemática (PUC-SP). Professor da Universidade Estadual de Montes Claros (Unimontes), Montes Claros, Minas Gerais, Brasil. Endereço para correspondencia: Avenida Rui Braga, s/n Prédio 3, Sala 3 - Vila Mauricéia, Montes Claros, MG, Brasil, CEP: 39401-089. E-mail: gilberto.januario@unimontes.br.

Doutora em Educação: Psicologia da Educação (PUC-SP). Professora da Pontifícia Universidade Católica de São Paulo (PUC-SP), São Paulo, SP, Brasil. Endereço para correspondencia: Rua Marquês de Paranaguá, 111 Consolação, São Paulo, SP, Brasil, CEP: 01303-050. E-mail: manrique@pucsp.br.

**** In memoriam. Doutora em Educação (USP). Professora da Universidade Cruzeiro do Sul (Unicsul) e professora colaboradora da Universidade Federal de Mato Grosso do Sul (UFMS).
} 
Data analysis shows that teachers knowledge, beliefs, and values influence information acquisition from curriculum materials, leading them to infer affordances, situate the agency in them and in the materials, and provoke the shift of power between the two agents. It also shows that affordances and agency can be collective skills provided by the exchange between teachers and their peers.

Keywords: Mathematics Education. Teacher-Curriculum Materials Relationship. Mathematics Curriculum. Affordance. Agency.

\section{Compreendendo o problema}

Como recursos que traduzem as prescrições oficiais em sequências de atividades, materiais curriculares têm sido a principal ferramenta que professores e estudantes lançam mão nos processos de ensino e de aprendizagem da Matemática, podendo ser livros didáticos, cadernos de atividades elaborados por Secretarias de Educação, materiais apostilados, fascículos, objetos de aprendizagem ou outras ferramentas tecnológicas. Esses recursos e o uso que professores fazem deles têm sido objeto de investigação em Educação Matemática.

No contexto norte-americano, um conjunto de pesquisas tem tomado a relação professor-materiais curriculares como foco de investigação com o propósito de entender como se dá essa relação, o papel do professor e dos materiais e como o uso desses recursos contribui nas reformas do ensino de Matemática. Nessas pesquisas há diferentes interesses de investigação, como, por exemplo, a relação entre materiais curriculares e desenvolvimento profissional (LLOYD, 1999; REMILLARD e GEIST, 1999; COLLOPY, 2003); a compreensão dos professores referente às orientações propostas nos materiais (LIN e FISHMAN, 2006); as crenças dos professores ao usar os materiais (MAWYER e EDELSON, 2007); a prática do professor ao desenvolver o currículo (BROWN, 2002; REMILLARD, 2005, 2012); e o aspecto educativo dos materiais curriculares (BALL e COHEN, 1996; SCHNEIDER e KRAJCIK, 2002; WANG e PAINE, 2003; DAVIS e KRAJCIK, 2005).

Investigando sobre como professores e materiais se relacionam, Brown e Edelson (2001), Brown (2002, 2009), Remillard (2005) e Charalambous e Hill (2012) discutem elementos que influenciam essa relação, destacando-se as affordances e a agência. Nesses estudos, as affordances assumem o significado de determinados aspectos dos materiais que potencializam seu uso, pelos professores, conforme foram elaborados; e a agência assume a conotação de poder de ação da relação, ora dando aos materiais a função de agentes, ora passando aos professores as decisões curriculares.

Nesse sentido, fortemente relacionados aos recursos dos professores e dos materiais são os conceitos de affordance e agência, que, quando explorados, permitem a investigação de 
informações e características que possibilitam compreender o que justifica diferentes usos de materiais curriculares e como esses recursos são concebidos por professores. Porém, é importante nos perguntarmos que aspectos caracterizam affordance e agência na interação entre professor e materiais curriculares.

Neste artigo, nosso objetivo é o de conceituar affordance e agência e discutir seus significados na relação professor-materiais curriculares em Educação Matemática. Para procedermos à conceitualização, realizamos busca de artigos e livros sobre a temática de investigação, seguida de uma triagem e posterior análise e exploração dos conceitos na perspectiva do estudo bibliográfico (FIORENTINI e LORENZATO, 2006). Em relação à discussão de significados, tomamos o relatório de uma pesquisa como objeto de estudo para realizar a análise de aspectos que possam ilustrar como esses conceitos estão associados à relação professor-materiais curriculares. Nesse caso, será produzida uma discussão na perspectiva da metanálise, em que o propósito é analisar e sintetizar os resultados de estudos já realizados, ressaltando novos aspectos e imprimindo nova interpretação à luz de fundamentação teórica (HUNTER e SCHMIDT, 2014).

O relatório citado refere-se ao projeto de pesquisa Avaliação de Professores do Ensino Fundamental da Secretaria Municipal de Educação de São Paulo, em relação a documentos e materiais de apoio à organização curricular na área de Educação Matemática, desenvolvido em 2011 e 2012, envolvendo duas pesquisadoras responsáveis, oito pesquisadores colaboradores e 31 professores que ensinavam Matemática na rede municipal de ensino de São Paulo.

A participação dos professes se deu por adesão ao convite feito pela Secretaria Municipal de Educação de São Paulo (SME-SP) e a constituição do grupo teve como propósito compreender quais eram as contribuições que os materiais curriculares, chamados de Cadernos de Apoio e Aprendizagem (CAA), produzidos pela Secretaria, poderiam trazer para as experiências pedagógicas inovadoras das escolas da rede municipal de ensino de São Paulo. Na realização do projeto, utilizou-se da estratégia de grupo focal como opção metodológica, sob a qual os professores foram agrupados tendo como referência os anos de escolaridade em que lecionavam. As reuniões eram realizadas aos sábados, com periodicidade quinzenal.

Em cada reunião, os professores estudavam temas relacionados à Educação Matemática, analisavam as sequências de atividades que compõem cada uma das oito unidades dos CAA de Matemática (referente ao ano correspondente ao agrupamento) e discutiam e planejavam seu desenvolvimento em sala de aula. No encontro seguinte, eram 
socializadas as experiências realizadas nas situações de aula, com o uso do Caderno, seguido de discussão, análise e planejamento de nova sequência de atividades.

Ao final do desenvolvimento de cada unidade de ensino do Caderno, os professores produziam um relatório, em que descreviam a realização das atividades. De posse desses relatórios, o pesquisador-colaborador responsável pelo agrupamento produzia um relatóriosíntese do desenvolvimento da unidade de ensino. Ao final do projeto, as pesquisadoras responsáveis reuniram os relatórios-síntese de cada agrupamento de professores $\left(1^{\circ}\right.$ ao $3^{\circ}$ e $5^{\circ}$ ao $9^{\circ}$ ano do Ensino Fundamental) e compilaram no relatório geral.

Colocados dessa forma, é sobre esses conceitos e problemas que tratará o presente artigo, que é organizado em quatro partes. Na primeira exploramos o conceito de affordance; na segunda, fazemos discussão de seu significado em materiais curriculares de Matemática; posteriormente, retratamos o conceito de agência. Na quarta parte, discutimos como esse conceito é relacionado a professores e a materiais curriculares. Por fim, apresentamos nossas considerações.

\section{Explorando o conceito de affordance}

Em uma interação, tanto o ambiente e seus objetos, quanto o indivíduo trazem aspectos de si para essa ação. Na interação com o ambiente e seus objetos, o indivíduo capta as informações por diferentes sistemas, especialmente pelo sistema visual, a partir de suas intenções e capacidades, e de informações disponíveis no ambiente e nos objetos.

As possibilidades de percepção de propriedades que um determinado ambiente ou objeto oferecem, referentes a sua ação, e que são captadas pelo indivíduo são chamadas de affordance (GIBSON, 1966). Essa expressão tem origem nas investigações sobre Ecologia, área em que se estuda a relação entre elementos de um ecossistema e um ou mais de seus organismos e, portanto, representa a complementariedade entre indivíduo e objeto (MORAES, 2008).

O termo affordance foi criado pelo psicólogo James Jerome Gibson, especialista em percepção visual e considerado o promotor da Psicologia Ecológica. Também conhecida por Psicologia Ambiental ou Ecopsicologia, a Psicologia Ecológica tem como objeto de estudo o dinamismo e a reciprocidade entre organismo (indivíduo) e ambiente ecológico (ambiente ou objeto), ou seja, investiga o comportamento da relação indivíduo e objetos de um espaço/ecossistema.

A origem desse termo remete à área da Psicologia conhecida como Gestalt, 
especificamente à expressão alemã aufforderungscharakter, traduzida para o inglês como invitation character, com o significado de serem as características que determinado objeto ou ambiente demandam para o sujeito que o observa (GIBSON, E. e PICK, 2000).

Para Gibson (1966, p. 126), a forma de percepção do ambiente e seus objetos é orientada para ações sobre eles, por isso, define affordance como aquilo que o ambiente ou objeto oportunizam ao indivíduo (ser humano ou animal) como possibilidades de ações, em que "a affordance implica a complementaridade do animal e do meio ambiente". Para Eleanor Jack Gibson, esposa e também psicóloga, essas possibilidades estão relacionadas à capacidade do observador em realizá-las.

Ainda no entender de Gibson, E. (1988), affordance conecta percepção à ação e à cognição, por estar relacionada ao significado dos objetos: o significado está no objeto e na mente do indivíduo e envolve a adequação da relação indivíduo-objeto.

A partir do que consideram Gibson (1966, 1977, 1986) e Gibson, E. (1988), entendemos que materiais curriculares, como objeto, têm características e propriedades que oportunizam aos professores, indivíduos, possibilidades que conectam percepção e aspectos cognitivos desses profissionais às ações (usos) dos materiais. Para esses autores, da observação das características que faz com que o indivíduo perceba affordances é possível determinar graus de intensidade.

Disso implica considerar que, ao se relacionar com materiais curriculares, os professores têm condições de perceber mais affordances do que um estudante. Isso acontece devido à capacidade de abstração e percepção e ao conhecimento de Matemática, de questões didático-metodológicas e de aspectos curriculares, que permitem ao professor, em comparação a um estudante, maior exploração das affordances dos materiais, de fragmentos dos materiais, dos princípios e opções teóricas subjacentes, da organização e apresentação dos conteúdos e da perspectiva de formação implícita nos materiais curriculares.

Gibson $(1979,1986)$ considera que a percepção de affordance é algo holístico e o que se percebe em um ambiente ou objeto não são suas qualidades ou propriedades, mas suas affordances, pois o objeto significa para o indivíduo apenas o que ele percebe, configurandose como produto das relações entre aspectos físicos do objeto e aspectos cognitivos do indivíduo. Desse modo, o indivíduo identifica o comportamento associado às características do objeto e não suas qualidades ou estrutura. Affordances não dependem do indivíduo; sejam percebidas ou não, elas existem como oportunidades de ação do indivíduo sobre o objeto.

Conforme já mencionamos, indivíduos têm diferentes percursos de aprendizagem e de conhecimento, que intervêm nos modos como percebem affordances. Assim, por exemplo, o 
desígnio de uma cadeira é o assento, mas pode ser utilizada como suporte para se alcançar determinado objeto; o desígnio de um compasso é construir lugares geométricos, mas pode servir como objeto perfurador; o desígnio de um aplicativo pedagógico é promover aprendizagem, mas pode ser utilizado como passatempo; o desígnio de uma atividade, presente no material curricular, é desencadear processos de resolução de problemas, discussão e construção de aprendizagens, mas pode ser concebida como lista de exercício para treinar procedimentos.

Na perspectiva de ecossistema proposto por Gibson $(1979$, 1986), o indivíduo, ao perceber affordances, percebe a si mesmo a partir da tomada de consciência de suas capacidades físicas e intelectuais e o tipo de ação determina hábitos, modos e tendência desse ecossistema que integra reciprocamente indivíduo e objeto. Nesse sentido, ao nos depararmos com um livro didático, o cenário formado em nossa mente é um ambiente de aula e as possibilidades de desenvolvimento das atividades. Tal recurso não carrega em si uma identidade que nos remeta a um culto religioso, por exemplo.

Pela perspectiva da psicologia ecológica discutida por Gibson (1986), na interação com o ambiente e seus objetos, o indivíduo capta informações que o fazem adquirir uma identidade e, como consequência, percebe as affordances disponíveis. Isso nos leva a considerar que, na relação com materiais curriculares, os professores podem identificar informações contidas nesses recursos e, de posse de seus conhecimentos, crenças e princípios, assumirem uma identidade e perceberem affordances nos materiais. Consideramos, ainda, que essas affordances balizam a prática do desenvolvimento curricular por meio dos materiais, ou seja, delimitam diferentes usos dos recursos curriculares, como ponderam Brown (2002, 2009) e Remillard (2005).

Em relação a diferentes usos (relação) de um objeto, Gibson (1986) nos ajuda a compreender que um ambiente, ou objeto desse ambiente, oferece diferentes tipos de affordances, constituindo-se em um rol de possibilidades para a interação com o indivíduo que o observa e o explora. Nessa perspectiva, esse autor expõe que

$$
\begin{aligned}
& \text { as diferentes substâncias do meio ambiente têm diferentes affordances para nutrição } \\
& \text { e para manufatura. Os diferentes objetos do meio ambiente têm diferentes } \\
& \text { affordances para manuseio. Os outros animais possibilitam, acima de tudo, um } \\
& \text { conjunto rico e complexo de interações, sexual, predatória, de luta, lazer, cooperação } \\
& \text { e comunicação. O que outras pessoas possibilitam constitui a totalidade real da } \\
& \text { importância social para os seres humanos. Nós prestamos atenção mais } \\
& \text { detalhadamente na informação visual e acústica que especifica o que a outra pessoa } \\
& \text { é, solicita, prenuncia e faz (GIBSON, 1986, p. 128). }
\end{aligned}
$$

As informações dos objetos são responsáveis pela inferência de affordances pelo indivíduo que os observa e planeja explorá-los. No entender de Gibson (1966, 1977), embora 
essas informações possam se dar pelo som, odor ou toque, são as informações visuais que controlam o comportamento do sujeito observador; trata-se de informação externa ao indivíduo, disponível no objeto para ser apreendida pela percepção visual.

O ambiente e seus objetos são vulneráveis a mudanças de diferentes ordens que alteram e balizam o comportamento do indivíduo. Por ser um processo dinâmico, o indivíduo também intervém e altera objetos e seus ambientes com o propósito de perceber affordances que satisfaçam suas necessidades. A depender do tipo de objeto considerado, materiais curriculares, por exemplo, as mudanças referem-se a concepções de seus idealizadores e de seus entendimentos sobre a educação dos indivíduos, que direcionam as ações dos professores sobre os recursos. Por outro lado, professores que ensinam Matemática lançam mão de seus conhecimentos, crenças e princípios e, com isso, intervêm nos materiais, inferindo affordances. Nesse caso, que informações podem disponibilizar os materiais curriculares de Matemática e como os professores percebem affordances neles?

\section{Affordance em materiais curriculares de Matemática}

Pela construção teórica da Psicologia Ecológica proposta por James Gibson, a percepção de affordance se dá a partir da captação de informações presentes no objeto e estas informações são responsáveis por estimular a sensibilidade ótica do indivíduo observador. Porém, a discussão de affordances em materiais curriculares de Matemática se dá pelo debate das informações presentes nesses materiais.

Embora essas informações possam ser identificadas por diferentes agentes - professor, estudante, coordenador pedagógico -, a percepção de affordances é um processo individual. Assim, ao analisar o relatório e as ponderações dos professores participantes do projeto de pesquisa, identificamos e discutimos informações que, para esses profissionais, possibilitaram a inferência de diferentes possibilidades de uso dos Cadernos de Apoio e Aprendizagem de Matemática (CAA), ou seja, de suas affordances.

Nesse sentido, todo material curricular é constituído por um conjunto de atividades e orientações para seu desenvolvimento. Nesse caso, a articulação entre as atividades e expectativas de aprendizagem é um fator que mostra aos professores como aquilo que foi planejado materializa-se em forma de atividades. Essa articulação é o que dá sentido às expectativas, ou objetivos, propostas pelo material curricular.

As atividades propostas para a expectativa M17 [Distinguir, em contextos variados, figuras

bidimensionais e tridimensionais, descrevendo algumas de suas características, estabelecendo 
relações entre elas e utilizando nomenclatura própria] foram consideradas interessantes pelos professores, uma vez que permitem e favorecem a construção de hipóteses sobre o espaço e sobre as formas que nos rodeiam, proporcionando o desenvolvimento do pensamento geométrico que envolve relações e representações tanto espaciais como planas, além do uso de nomenclatura apropriada. Essas atividades possibilitam a integração com grandezas $e$ medidas, mais especificamente com as expectativas M24 [Obter medidas de grandezas diversas, por meio de estimativas e aproximações e tomar decisão quanto a resultados razoáveis dependendo da situação-problema], M25 [Utilizar instrumentos de medida, como régua, esquadro, trena, relógios, cronômetros, balanças para fazer medições, selecionando os instrumentos e unidades de medida adequadas à precisão que se requerem, em função da situação-problema] e M26 [Realizar conversões entre algumas unidades de medida mais usuais (para comprimento, massa, capacidade, tempo) em resolução de situações-problema] (Relatório de Pesquisa, fragmento referente ao grupo dos professores do $6^{\circ}$ ano, 2013).

O fragmento destacado ilustra que a articulação entre diferentes expectativas potencializa os recursos dos materiais e as aprendizagens dos estudantes. A articulação configura-se como informação do material curricular de Matemática que, para ser captada, precisa que os professores mobilizem seus aspectos cognitivos para reconhecer elementos conceituais, didáticos e metodológicos que associam uma expectativa a outra. Da leitura do que teoriza Gibson (1979), é possível afirmar que, ao captar tal informação, os professores perceberam affordances para atender aos seus propósitos ao desenvolver o currículo e, portanto, interviram no material, ampliando sentidos e significados das atividades. Para Brown (2002), esses aspectos cognitivos são os recursos dos professores.

Ao analisarem o material curricular Caderno de Apoio e Aprendizagem de Matemática, os professores percebem valores e significados desses recursos, por meio de informações que estimulam as sensações e os levam a perceber possibilidades de uso. No fragmento seguinte, as affordances referem-se às articulações do material do $6^{\circ}$ ano do Ensino Fundamental, especificamente da Unidade 4, com outros recursos disponíveis na escola e à organização dos conteúdos.

[Os professores] acrescentaram, ainda, a possibilidade de articulação e complementação com outros materiais, como livros didáticos adotados pela escola e a organização dos conteúdos que aborda diferentes eixos (blocos) do conhecimento matemático (geometria, números e operações, grandezas e medidas, tratamento da informação) (Relatório de Pesquisa, fragmento referente ao grupo dos professores do $6^{\circ}$ ano, 2013).

Em outra parte do Relatório de Pesquisa, encontramos ponderação do grupo de professores do $8^{\circ}$ ano do Ensino Fundamental referente à articulação entre o Caderno e ferramentas tecnológicas, permitindo aos estudantes explorar softwares que facilitassem a leitura de dados e a elaboração de conclusões, como podemos observar no excerto seguinte:

A professora [...] ressalta que além das questões matemáticas, as atividades apresentadas pelo CAA com proposta de utilização de planilhas eletrônicas (por exemplo, o Excel) geram a possibilidade de trabalho com estética de gráficos, formulação de perguntas. Estratégias estas que possibilitam a discussão e interpretação de dados, uma vez que são facilitadores oriundos 
do próprio grupo: "[...] trabalhamos com a estética da tabela e do gráfico, como por exemplo, cores, fontes, modelos de tabelas, com muitas intervenções, pois não possuíam familiaridade com as ferramentas da informática; formularam perguntas referentes ao gráfico construido de modo que o colega compreendesse com a leitura do gráfico" (Relatório de Pesquisa, fragmento referente ao grupo dos professores do $8^{\circ}$ ano).

Ao planejar o desenvolvimento das atividades a partir da articulação com outros materiais, inclusive artefatos tecnológicos, e interrelacionar conteúdos de diferentes blocos, os professores perceberam o que Gibson (1986) chama de rol de possibilidades de ação, que proporciona diferentes interatividades entre eles e os Cadernos - reprodução, adaptação e improvisação -, como expõe Brown (2002, 2009).

Conceber diferentes tipos de usos dos materiais curriculares implica considerar que, na concepção da Psicologia Ecológica, os professores ganham identidade a partir da captação de informações e, a partir disso, percebem affordances nos materiais. Diante do que discute Gibson, E. (1988), é possível afirmar que a informação está no material curricular, objeto, mas é processada pela ação cognitiva do professor, indivíduo, que mobiliza conhecimentos, crenças e princípios para aferir affordances.

Nesse sentido, duas informações destacadas pelos professores participantes do projeto de pesquisa como referência para suas práticas ao usar os Cadernos são as orientações presentes nos materiais e o estímulo às intervenções para mediar/promover situações de aprendizagem. Essas orientações geralmente apresentam o quanto, e como, os elaboradores desses materiais explicitam aspectos conceituais, didáticos e metodológicos das atividades. Elas podem ser traduzidas como um diálogo entre elaboradores e professores e têm o propósito de engajar os docentes no desenvolvimento curricular, por antecipar possíveis dúvidas dos estudantes, indicar diferentes modos de resolução, apresentar formas variadas de abordagem dos conteúdos e sugerir possíveis intervenções. No entender de Stein e Kim (2009, p. 44),

\begin{abstract}
os elaboradores de materiais curriculares projetam propositalmente atividades que orientam os estudantes para situações particulares que eles acreditam que irão ajudar a aprender uma habilidade ou alcançar um insight de alguns aspectos da Matemática. [...] Quando os elaboradores conversam diretamente com os professores sobre as ideias matemáticas e pedagógicas subjacentes a estas tarefas - desse modo fazendo suas agendas e perspectivas acessíveis - nos referimos aos materiais curriculares como transparentes.
\end{abstract}

As affordances referentes à transparência foram inferidas pelos professores participantes porque tal informação está nos materiais curriculares. Ao se identificar com as orientações, os professores se reconhecem como profissionais que desenvolvem o currículo por meio de práticas que vão ao encontro ao que propõem os elaboradores dos materiais. Assim, os Cadernos de Apoio e Aprendizagem são percebidos pelos professores que os usam, 
que tomam, então, consciência de si e de suas possibilidades de ação ou, nas palavras de Gibson (1986, p. 111), "quando um homem vê o mundo, ele vê o seu nariz ao mesmo tempo [...] o mundo e o seu nariz são ambos especificados [...]”.

Afirmar que materiais curriculares e professores, inseridos em um ecossistema, são específicos é considerar quais elementos de ambos se articulam: por um lado, as informações contidas nos materiais e, por outro, os professores com seus objetivos curriculares. Nesse sentido, a contextualização é uma informação dos materiais que possibilita a interação entre professores e os Cadernos de Apoio e Aprendizagem, especificando as possibilidades desses materiais conforme podemos observar no fragmento seguinte:

Outro ponto muito positivo dessa Unidade foi o fato de as atividades propostas estarem contextualizadas e representarem os usos sociais reais da Matemática (Relatório de Pesquisa, fragmento referente ao grupo dos professores do $5^{\circ}$ ano, 2013).

O fato de as atividades apresentarem situações que pretendem dialogar com situações do mundo e da vida dos estudantes é uma informação relevante para os professores por possibilitar uma prática articulada entre novos conceitos e práticas sociais dos estudantes, o que pode resultar em processo de aprendizagem mais significativo. No entanto, o aspecto contextualização é apenas uma informação que, captada pelos professores, indica maior envolvimento dos estudantes com as atividades e aprendizagem significativa, o que para Gibson $(1977,1986)$ caracteriza as possibilidades de ação desses recursos, portanto, suas affordances.

Como essas affordances, outras são inferidas pelos professores, como o reconhecimento da Matemática em contextos sociais; a mobilização de conhecimentos prévios; a atratividade da atividade; a elaboração e verificação de hipóteses; as interações sociais; e a construção de conceitos.

Outro fator preponderante para o atendimento das expectativas [...] se refere às ilustrações e ao colorido das imagens, algo que se mostrou atrativo para as crianças e necessário no trabalho com a contagem. As atividades acerca da resolução de problemas do campo aditivo, com o respaldo das imagens, contribuíram para a compreensão dos problemas de transformação negativa (Relatório de Pesquisa, fragmento referente ao grupo dos professores do $1^{\circ}$ ano, 2013).

Conforme podemos observar no excerto, as ilustrações têm o papel de tornar a atividade mais atrativa, pelas características das figuras e seu colorido, ou pela melhor compreensão que proporcionam em relação à redação da atividade. As ilustrações contribuem na interação dos estudantes com o material e, ao promover melhor compreensão das atividades, ajudam na construção de conceitos.

Da leitura do Relatório de Pesquisa, observamos nas ponderações dos professores que, 
conforme se dá a elaboração da atividade, no que se refere à redação e à disponibilização de dados, possibilidades de mobilização dos conhecimentos prévios dos estudantes, elaboração e verificação de hipóteses e socialização das estratégias pessoais são inferidas. Como affordances, observamos também a interação entre o que se propõe como novo e o que o estudante tem de conhecimento sobre aquilo que o leva a manifestar seus saberes; a elaborar, testar e validar hipóteses; e a comunicar-se com os demais colegas, trocando conhecimentos e construindo sentidos e significados a partir de um ambiente mediador.

A partir do que teoriza Gibson $(1979,1986)$, não são as qualidades ou propriedades que os professores identificam nos materiais curriculares, mas suas affordances. Assim, promover a construção de conceitos matemáticos, embora possa parecer o objetivo de quaisquer materiais - Cadernos de Apoio e Aprendizagem, por exemplo -, não é algo que dependa apenas de uma prescrição para esses recursos, mas também da possibilidade de ação; e, pela interação, portanto, são percebidas nos materiais a partir dos professores como "uma combinação específica de propriedades de sua substância e sua superfície tomada com referência a um animal [indivíduo]" (GIBSON, 1977, p. 67).

As affordances expressam a possibilidade dos materiais curriculares sensibilizar as percepções dos professores e a capacidade desses profissionais de perceberem o que está disponível a eles para desenvolverem o currículo e potencializá-lo como recurso promotor de processos de ensino e de aprendizagem.

Assim, da leitura do Relatório de Pesquisa, é possível identificar outros exemplos de affordances percebidas pelos professores participantes do projeto de pesquisa ao se relacionarem com os Cadernos de Apoio e Aprendizagem de Matemática: o desenvolvimento da afetividade dos estudantes, possibilitado por situações envolvendo familiares, lugares e animais; o sentimento de pertença, ou patriotismo, possibilitado por atividades que exploram aspectos da região onde residem os estudantes, o que, para os professores, mostra-se significante e desperta o interesse para o estudo dos conteúdos, à medida que se problematizam e se reconhecem os espaços da cidade; a interdisciplinaridade possibilitada por atividades que problematizam e discutem temas relacionados a outras áreas do saber, a fenômenos da atualidade e a ideias da própria Matemática; a elaboração de argumentos, justificativas e formulação de perguntas; o trabalho em equipe, as interações, o desenvolvimento de competências leitora e escritora; e o desenvolvimento da autonomia, do protagonismo e da autoria nos estudantes, possibilitados pelo modo como as consignas das atividades são elaboradas, como exemplifica o excerto seguinte.

$O$ modo como as atividades dos Cadernos de Apoio e Aprendizagem do $9^{\circ}$ ano estão 
organizadas permitiu aos estudantes refletir sobre as concepções que eles tinham em relação ao que é aprender e como aprender nas aulas de Matemática.

O desenvolvimento da autonomia foi outro aspecto que contribuiu para as aprendizagens dos estudantes. De acordo com a professora [...], as perguntas propostas nas atividades do CAA permitem a eles chegar às conclusões sem a necessidade de intervenção do professor (Relatório de Pesquisa, fragmentos referentes ao grupo dos professores do $9^{\circ}$ ano, 2013).

Ao relatarem as possibilidades do material curricular, como no fragmento anterior, os professores expõem o reconhecimento de affordances. A partir do que discute Gibson (1966, 1986) em sua construção teórica, sabemos que as affordances são, dos materiais, fonte impregnada de informações que servem de estímulo para que professores, a partir de seus conhecimentos, crenças e princípios, percebam diferentes possibilidades de uso. As affordances são determinadas, então, pela relação professor-materiais curriculares na qual, como elementos dinâmicos, ambos implicam e são implicados no desenvolvimento curricular a partir de características que determinam o poder de decisão. Esse conjunto de características, traduzido como agência, é o conceito que passaremos a explorar.

\section{Explorando o conceito de agência}

A ideia de poder, ou de autoridade, sobre uma decisão tem sido associada ao conceito de agência como a possibilidade de produzir efeitos no mundo e nas relações sociais e influenciar mudança nessas relações. Esse conceito tem sido foco de discussão em diferentes áreas do conhecimento ao tomar o contexto social, as relações sociais e seus sujeitos.

Do latim agentia, refere-se à capacidade de ação de um sujeito em relação ao mundo que habita, interage e explora; é a competência pertinente ao agente, aquele ou aquilo que age (BARKER, 2008). Ao discutir agência como a capacidade para a ação, inerente ao agente, Stones $(2010$, p. 13) concebe essa noção como "o elemento dinâmico dentro do ator que traduz a capacidade potencial em prática concreta", em que essa capacidade de agir está a favor do próprio ator, ou agente.

Relacionada ao conceito de agência, está a noção de estrutura, constituída de fatores que influenciam a capacidade de autoridade e de ação nas relações sociais. Esses fatores podem ser a cultura, a nacionalidade, o gênero, a etnia, a escolaridade, a classe social, as concepções de diferentes aspectos, entre outros.

Agência e estrutura têm sido estudados no campo da Sociologia como termos que explicam as relações estabelecidas no contexto social. Dentre os autores que discutem o assunto, o britânico Anthony Giddens propôs discussões referentes ao estruturacionismo, 
perspectiva para teorizar sobre estrutura e agência.

Na concepção de Giddens (1975, 1991), a estrutura é um sistema composto por regras, recursos, limites e possibilidades, e a estruturação, como união de estrutura e ação, refere-se ao processo das relações sociais, em que essas se alicerçam no tempo e no espaço. $\mathrm{Na}$ estruturação, o agente - ou ator - é aquele que coordena suas atividades e regula aspectos físicos e sociais nos contextos em que realiza ações; a agência, por sua vez,

não se refere às intenções que as pessoas têm ao fazer as coisas, mas à capacidade delas para realizar essas coisas em primeiro lugar (sendo por isso que "agência" subentende poder: conforme uma definição de agente do Oxford English Dictionary como "alguém que exerce poder ou produz efeito") (GIDDENS, 1989, p. 10).

Nesse sentido, a agência, como uma competência humana, é a forma pela qual se exerce o poder em toda e qualquer ação, em que esse poder está associado à capacidade transformadora e inclui a causalidade pelo agente. Trata-se da capacidade de interferir em eventos das relações sociais, não necessariamente com intencionalidade. Para Giddens (1989, p. 14), mais do que intencionar algo, o agir é significativo em sua ocorrência, uma vez que a “ação depende da capacidade do indivíduo de 'fazer uma diferença' em um estado préexistente de coisas ou curso de eventos".

$\mathrm{Na}$ concepção de agente como sujeito cognitivo, os conceitos de consciência discursiva e consciência prática estão relacionados às capacidades cognoscitivas, definidos como "[...] o que pode ser dito e o que, de modo característico, é simplesmente feito" (GIDDENS, 1989, p. 8). A consciência discursiva refere-se ao que o agente manifesta verbalmente sobre seu modo de conceber o mundo e as relações, sua própria prática e suas crenças. A consciência prática relaciona-se às ações realizadas pelo agente sem seu discernimento, ou explicação, dos motivos de sua conduta.

Giddens (1989) concebe o agente como um sociólogo, à medida que ele entende, pensa e reflete sobre suas práticas e as dos outros. Assim, "o conhecimento que eles possuem não é secundário para a padronização persistente da vida social, mas faz parte dela" (GIDDENS, 1989, p. 31).

Quanto ao nosso tema de estudo, professores que ensinam Matemática, como agentes do desenvolvimento curricular, manifestam suas agências ao se relacionarem com os materiais e imprimirem, nessa relação, autoridade de escolhas e de decisões referentes a diferentes aspectos, como sequência de conteúdos e atividades, abordagem metodológica, gestão da aula (organização de tempos e espaços) e intervenções e encaminhamentos, a partir das dúvidas dos estudantes.

Embora essas ações sejam comuns a todos os profissionais que exercem a docência, a 
capacidade de agência é diferenciada por diferentes fatores, chamados por Giddens (1989, 2001, 2010) de estrutura, como os conhecimentos, as crenças e princípios dos professores sobre a Matemática, os materiais curriculares e o percurso de aprendizagem dos estudantes. Desse modo, não há como analisar a agência separadamente da estrutura na qual esta se insere, pois esses dois conceitos "longe de serem opostos, de fato se pressupõem mutuamente" (SEWLL JR., 1992, p. 4). Ainda sobre essas duas noções, Mouzelis (2008) pondera que indivíduos com maiores recursos possuem maior grau de agência do que outros que apresentam volume reduzido.

A agência de um ser humano é compreendida como as capacidades ou habilidades que os indivíduos têm para agir em uma situação, interagindo com o ambiente e seus objetos, com outros indivíduos e com a estrutura do espaço social (GIDDENS, 1991, 1997). No entender de Barker (2008), essas competências e habilidades são afetadas por aspectos cognitivos que envolvem crenças dos indivíduos; percepções e representações sustentadas pela sociedade e pelo indivíduo; estrutura e possibilidades de um espaço social no qual o indivíduo está inserido; e posição cultural, social e econômica a que o indivíduo pertence.

$\mathrm{Na}$ perspectiva das relações sociais e dos contextos ou fenômenos que influenciam essas relações, o conceito de agência não se limita apenas ao sujeito cognoscente, associandose a seres humanos, animais, objetos, instituições, ambientes. Nesse sentido, Santin (2015) pondera que aos termos agente ou agência associam-se três núcleos: fazeres, referente à agência inanimada; atos, relacionado ao agente animado; e ações, relativo a humano, embora os agentes humanos também tenham seus fazeres e atos.

A agência inanimada relaciona-se a substâncias e objetos físicos que provocam alteração em outros objetos sem a interferência de um terceiro elemento. Como exemplo, Santin $(2015$, p. 21) cita "o ácido que corrói a placa de metal por contato, a água que dilui o cubo de açúcar nela imerso, o tijolo que quebra a janela".

A agência animada é intermediária entre as agências inanimada e humana e pode ser caracterizada pelas ações e reações provocadas por um agente com ou sem intencionalidade. Os atos, nesse sentido, são praticados pela conveniência da ocasião e, por isso, a agência animada pode ser "aplicada a animais, mecanismos e artefatos. Assim, dizemos que o cão obedeceu ao comando para ganhar o biscoito, que o relógio marca precisamente o horário" (SANTIN, 2015, p. 21).

Como já destacamos, a agência humana refere-se à capacidade de espontaneidade do ser humano, ou seja, de praticar uma ação por vontade e iniciativa própria ou por impulso do momento ou das circunstâncias (SANTIN, 2015). Desse modo, Hacker (2010, p. 148) 
pondera sobre essa capacidade humana, explicitando que

o horizonte da ação de agentes racionais coincide com o domínio de sua vontade.
Assim, apenas agentes volitivos podem ser ditos que agem e encetam a ação. Seria
um erro supor que sempre que um agente age, ele enceta a ação. Encetar a ação é
agir voluntariamente em resposta à circunstância (por exemplo, uma ameaça ou
perigo percebido) ou em busca de uma meta, dada a percepção da oportunidade. [...]
Apenas um ser que pode encetar a ação pode agir, pois uma criatura que pode fazer
ou deixar de fazer algo voluntariamente, que pode ter e aproveitar uma oportunidade
(bem como perder uma), que pode optar por ou escolher um curso de ação sobre
outro.

Se toda ação causa uma reação, as noções de agência associam-se à causalidade, que inclui, por sua vez, a autoridade sobre uma decisão. Assim, a exploração do conceito de agência perpassa pelo conceito de poder e/ou autoridade sobre escolhas e decisões.

No desenvolvimento curricular, a agência refere-se à autoridade de escolha sobre elementos da Matemática e de seu ensino, como discutem McClain, Zhao, Visnovska e Bowen (2009). Quanto à Matemática, a agência refere-se às escolhas de conteúdos a serem ensinados; em relação ao seu ensino, a agência refere-se à organização e seleção dos conteúdos, ao tratamento didático-metodológico e aos aspetos conceituais.

Nesse sentido, do que teoriza Anthony Giddens, podemos afirmar que professores e materiais curriculares têm autoridade de escolha sobre o desenvolvimento curricular, referente à Matemática e ao seu ensino. Como agência humana, os professores exercem seu poder e tomam decisões a partir de suas concepções, crenças e valores da Matemática, dos materiais e dos processos de ensino e de aprendizagem. Como agência animada, os materiais curriculares exercem seu poder de decisão a partir das concepções, crenças e valores da Matemática, dos materiais e dos processos de ensino e de aprendizagem de seus elaboradores; da inclusão de orientações dos currículos prescritos; e das qualidades físicas e gráficas. Esses aspectos se materializam nas situações de aprendizagem e nas sugestões de realização dessas situações.

Ao considerar o desenvolvimento curricular e, em especial, a relação professormateriais curriculares como um processo dinâmico em que ambos, com seus recursos (BROWN, 2002, 2009), determinam ações que implicam tipos diferenciados de usos, é pertinente compreendermos quais elementos caracterizam agência nos professores e nos materiais e como ocorre seu deslocamento entre esses dois agentes.

\section{Agência no professor e nos materiais curriculares de Matemática}

A abordagem do conceito de agência nos materiais curriculares ou nos professores passa pela discussão de elementos, de cada um desses dois agentes, que caracterizam 
competências que influenciam ou determinam o poder de decisão sobre a Matemática e seu ensino. Essas competências referem-se à capacidade de potencial da realização de práticas a favor de si próprio nas relações estabelecidas (desenvolvimento curricular) em um determinado contexto social (situações de aula em um espaço educacional).

Considerarmos que no desenvolvimento curricular cada um desses agentes imprime autoridade sobre a Matemática e seu ensino implica ponderar que cada um demanda elementos que caracterizam a agência. Nesse sentido, ao analisar o Relatório de Pesquisa e, especificamente, as ponderações dos professores participantes do projeto, buscamos identificar elementos que esses profissionais avaliaram como decisivos ao mediar/promover situações de aprendizagem, isto é, a inferência de agência, conforme interpretamos à luz das teorizações de Anthony Giddens.

Em relação à agência nos materiais, um item que determina autoridade a esse recurso curricular é a coerência entre o que se propõe como expectativa de aprendizagem, ou objetivo, e as capacidades cognitivas dos estudantes. Essa coerência se traduz na adequação dos conteúdos propostos à faixa etária dos estudantes e ao que é esperado, socialmente, que certo grupo etário aprenda em determinado ano letivo.

Os professores do grupo concordam que a proposta de atividades colocadas pelo Caderno de Apoio e Aprendizagem vai ao encontro das expectativas de aprendizagem previstas para o ano/série. A forma com que as atividades foram apresentadas possibilitou uma crescente construção do conhecimento, de modo que uma atividade complementava a outra, dando à criança e também ao professor a clareza dos objetivos a que se propôs a unidade, facilitando a compreensão do assunto tratado, bem como a reflexão sobre o sistema de numeração decimal (Relatório de Pesquisa, fragmento referente ao grupo dos professores do $3^{\circ}$ ano, 2013).

Pela observação do excerto acima, a coerência entre expectativas e capacidade cognitiva dos estudantes está impressa nos materiais curriculares e é identificada pelos professores pelo modo como as atividades são apresentadas. Essa coerência é destacada por possibilitar articulação entre conceitos e procedimentos de diferentes atividades e, desse modo, levar os estudantes a construírem e avançarem em suas aprendizagens. Outro item destacado é a transparência do material, conforme discutem Stein e Kim (2009), identificada pela explicitação do que objetivava a unidade de ensino e que informava ao professor o que se espera dele e dos estudantes em relação ao que propunha os materiais.

Ainda sobre o excerto destacado, ele ilustra a dialética do controle, um tipo de influência, denominado por Giddens (1989), que envolve um agente subalterno (o material curricular) e outro superior (o professor), em que, na relação de poder entre ambos, há uma diluição da autoridade, à medida que o agente menos influente imprime recursos que exercem 
maior controle sobre o agente mais poderoso. Assim, a transparência e coerência entre expectativas e capacidades cognitivas dos estudantes fazem dos materiais - Caderno de Apoio e Aprendizagem - agentes que exercem poder e transformam a prática pedagógica em situações de aula de Matemática, influenciando a prática (relação social) do professor.

A inferência de agência, destacada por Giddens (1993), é um processo realizado pelo agente com capacidade de exercer as decisões preferenciais nas relações situadas em um contexto social, como a situação de aula conforme entendemos. Desse modo, a forma como as atividades são elaboradas implica o desenvolvimento curricular e o modo como os professores se relacionam com os materiais.

Ainda sobre a dialética do controle, atividades contextualizadas interferem significativamente nas decisões curriculares e na apreciação do material pelos professores, como podemos observar no fragmento seguinte.

As professoras destacaram que, especialmente as atividades propostas na Unidade VI, são abordadas temáticas próximas ao cotidiano das crianças como, por exemplo, cenas do dia-adia em que se faça necessário o uso da contagem, das relações sobre o tempo (dias, semanas e meses) e do jogo da trilha, que propõe o trabalho articulado entre o lúdico e a Matemática. Desta forma, a contextualização e os recursos metodológicos, sugeridos no caderno de apoio, foram apontados pelo grupo como fatores que influenciaram no atendimento das expectativas de aprendizagem (Relatório de Pesquisa, fragmento referente ao grupo dos professores do $1^{\circ}$ ano, 2013).

Da análise do Relatório de Pesquisa, entendemos haver consenso de que a contextualização potencializa as aprendizagens por associar ideias e situações novas, no material, a práticas sociais dos estudantes. A contextualização, nessa perspectiva, engaja os estudantes na problematização de aspectos possivelmente vivenciados por eles em sociedade, na busca da Matemática como meio para solucionar e compreender problemas da realidade social e na percepção de que a Matemática, por meio de seus conceitos, está aplicada ao mundo real. A contextualização, então, imprime agência nos materiais e eles, por sua vez, exercem o poder sobre o desenvolvimento curricular, levando o professor a ter fidelidade sobre esses recursos, reproduzindo ou criando situações de aprendizagem a partir deles (BROWN, 2002; REMILLARD, 2005).

Do entendimento do binômio professor-material curricular, a ação realizada por ambos os agentes no desenvolvimento curricular é socioculturalmente mediada em sua produção e interpretação. A agência, nessa perspectiva, "refere-se à capacidade de agir socioculturalmente mediada" (AHEARN, 2001, p. 112), uma vez que a Matemática, e seu ensino, e as práticas sociais estão intimamente relacionadas e implicam o modo de conceber e agir nos processos de ensino e de aprendizagem. 
Ainda sobre a agência nos materiais curriculares, encontramos no Relatório de Pesquisa ponderações, dos professores participantes do projeto, em relação a características que empoderam os Cadernos de Apoio e Aprendizagem de Matemática, como sendo atividades que investem na mobilização dos conhecimentos prévios dos estudantes.

Os professores afirmam que as atividades da unidade 4 estão adequadas às expectativas de aprendizagem propostas. Justificam que os exercícios e a sequência das atividades estão num formato que leva realmente o aluno a utilizar seus conhecimentos prévios adquiridos anteriormente e conseguem explorar realmente o que se propôs" (Professora [...]) ou ainda, "porque são situações que os alunos conseguem entender como reais em sua rotina" (Professora [...]) (Relatório de Pesquisa, fragmento referente ao grupo dos professores do $8^{\circ}$ ano, 2013).

Pelo que consideraram os professores, e conforme podemos observar no excerto acima, a mobilização de conhecimentos prévios engaja os estudantes a articularem aprendizagens construídas em diferentes contextos, inclusive fora do espaço escolar, no processo de compreensão e resolução das atividades. Assim, o Caderno de Apoio e Aprendizagem passa a ter o poder sobre o currículo por levar o aluno a manifestar conhecimentos prévios e por tomá-los como ponto de partida para novas situações de aprendizagem.

Nessas novas situações, outras habilidades - a serem desenvolvidas/potencializadas nos estudantes - são propostas no material e caracterizam agência nele, como a criação, testagem e validação de hipóteses; a manifestação de diferentes estratégias de resolução de uma atividade; a troca de experiências e descobertas com os colegas da turma; as interações sociais nas situações de aula; a postura investigativa; a leitura e escrita para comunicar a produção de conhecimento; o tipo de linguagem e o jogo de palavras que propiciam melhor entendimento sobre as consignas.

Quanto à agência nos professores, essa é entendida como agência humana (GIDDENS, 1989; SANTIN, 2015), referente à capacidade para influenciar as ações, como esforço individual (agência pessoal) ou como empenho de um grupo (agência coletiva). O professor como “'agente' ou 'ator' [é] o sujeito humano total, localizado no tempo-espaço corpóreo do organismo vivo", que interage com intencionalidade no contexto social, com consequência intencional ou não (GIDDENS, 1989, p. 59).

As ações ocorrem no desenvolvimento curricular, na relação com os materiais curriculares de Matemática, em que o propósito é mediar/promover situações de aprendizagem. Essas ações apresentam elementos que caracterizam modos do professor, individual ou coletivamente, de exercer sua autoridade de escolha e de decisão sobre o currículo a ser realizado em situações de aula, ou seja, caracterizam a agência. 
Ao analisar os materiais curriculares, Cadernos de Apoio e Aprendizagem, os professores identificam restrições, fragilidades ou lacunas, e planejam intervenções para que expectativas, ou objetivos, sejam contemplados pelas atividades. A identificação e o planejamento aqui destacados se dão por meio de conhecimentos adquiridos a partir de suas experiências com a docência; de suas hipóteses sobre o processo de aprendizagem dos estudantes; e da antecipação das dúvidas da turma.

As expectativas de aprendizagem propostas estavam adequadas às sequências de atividades sugeridas, no entanto em algumas sequências o grupo de professores acrescentou outras expectativas além das que estavam previstas inicialmente na atividade.

Em relação à "Agora, é com você" não havia necessidade da atividade 1 ser feita com calculadora, uma vez que o objetivo é que os alunos possam fazê-la sozinhos (Relatório de Pesquisa, fragmentos referentes ao grupo dos professores do $2^{\circ}$ ano, 2013).

Os excertos acima ilustram como os professores mobilizam seus conhecimentos para identificar expectativas não elencadas no material, o que os leva a perceberem outras. A agência aqui é identificada pela mobilização de conhecimentos referentes à Matemática (conteúdos) e ao seu ensino, especificamente em relação ao uso de artefatos para ajudar os estudantes na construção de suas aprendizagens.

No exemplo destacado, os professores mostram seu poder sobre o uso do material, ou sobre o currículo, ao determinarem que um recurso tecnológico, a depender do que objetiva uma atividade, pode dificultar a compreensão dos estudantes sobre os conceitos envolvidos. Isso mostra o conhecimento do professor sobre o conteúdo e sobre o que é esperado do estudante, resultando na relação como subversão entre professor e currículo (REMILLARD, 2005).

Giddens (1991, 1997) nos ajuda a compreender essa relação com os materiais curriculares como uma ação fruto da intervenção de agentes que controlam não só suas próprias práticas - aqui entendidas como escolhas e decisões sobre o material -, mas também atividades de outros agentes, compreendidas como os modos dos estudantes de se relacionarem com as atividades, recorrendo ou não a materiais manipulativos. No excerto anterior, ao decidirem sobre o uso ou não da calculadora, os professores regulam as práticas dos estudantes, reproduzindo condições que tornam o material curricular possível conforme suas concepções sobre o percurso de aprendizagem da turma.

A professora [...] afirma que quase sempre explica os conteúdos antes de desenvolver as atividades (Relatório de Pesquisa, fragmento referente ao grupo dos professores do $7^{\circ}$ ano, 2013).

Para alguns professores a atividade "Agora, é com você" foi utilizada como estratégia inicial para início desta unidade vista como retomada dos pontos principais da unidade anterior 
(Relatório de Pesquisa, fragmento referente ao grupo dos professores do $8^{\circ}$ ano, 2013).

A depender da concepção do material curricular, as atividades são apresentadas com um determinado propósito. No caso do Caderno de Apoio e Aprendizagem, o objetivo é que os estudantes mobilizem diferentes conhecimentos, elaborem estratégias e construam aprendizagens. Os professores, de posse de seus conhecimentos e de suas hipóteses sobre as aprendizagens dos estudantes e baseados em seus objetivos ao desenvolver o currículo, imprimem poder sobre o material curricular, alterando sequenciação das atividades, como no fragmento do grupo de professores do $8^{\circ}$ ano, inclusão ou exclusão de situações-problema, ou antecipam explicações, como no fragmento do grupo de professores do $7^{\circ}$ ano do Ensino Fundamental.

A ação de antecipar explicações assenta-se na compreensão dos professores de que seus estudantes têm menos dificuldade nas resoluções e maior facilidade na construção dos conceitos envolvidos nas atividades. Conforme o que teoriza Giddens (1993), a agência nesse caso se configura como prática contínua e dinâmica que resulta na intenção e nos objetivos do agente (professor) ao desenvolver o currículo. Nesse sentido, esse autor considera “'intencional' ou 'determinante' qualquer ato que o agente saiba (acredite) que possa manifestar uma determinada qualidade ou resultado, e em que esse conhecimento seja usado pelo ator para produzir essa qualidade ou resultado" (GIDDENS, 1993, p. 83).

Conhecimentos, crenças e valores da Matemática, de seu ensino e das aprendizagens dos estudantes, empoderam os professores na tomada de decisões ao usar os materiais curriculares, a buscar outros materiais e a redimensionar as atividades para promover sentidos e significados, em seus estudantes, relacionados aos conceitos.

Ao organizar as expectativas quanto ao bloco "Espaço e Forma", no que se refere às competências e habilidades relacionadas à percepção e compreensão das formas geométricas, os professores evidenciaram um percurso de aprendizagem mais amplo, pois para eles as atividades sugeridas no Caderno de Apoio e Aprendizagem são insuficientes para a concretização das expectativas a elas relacionadas (Relatório de Pesquisa, fragmento referente ao grupo dos professores do $3^{\circ}$ ano, 2013).

No que diz respeito ao princípio da igualdade e da relação inversa nas equações de primeiro grau, os professores apontam que inicialmente trabalharam com as equações privilegiando a atividade que envolvia o argumento de balança e posteriormente a questão da operação inversa, porque acreditam que a ideia do equilíbrio deve preceder a resolução algébrica propriamente dita (Relatório de Pesquisa, fragmento referente ao grupo dos professores do $8^{\circ}$ ano, 2013).

Os dois excertos mostram a relação dos professores com o Caderno de Apoio e Aprendizagem por meio de adaptações (BROWN, 2002, 2009) em que se subverte o currículo proposto por seus elaboradores (REMILLARD, 2005). A adaptação e a subversão são 
possibilitadas pela agência nos professores, implicada pelos conhecimentos docentes sobre o conteúdo, por sua apresentação (organização, sequenciação, abordagem) e pelo aspecto conceitual, como ilustra o fragmento do grupo de professores do $8^{\circ}$ ano. Também são saberes relativos a aspectos didático-metodológicos os que levaram o grupo de professores do $7^{\circ}$ ano a adaptar o material para que as atividades pudessem suscitar sentidos e significados à percepção de características e propriedades de sólidos geométricos.

Conhecimentos, crenças e valores dos professores sobre a Matemática, os materiais curriculares e os processos de ensino e de aprendizagem são fatores que influenciam os modos como esses profissionais exercem poder ao usarem os materiais e desenvolverem o currículo. Esses fatores oportunizam o que Giddens (1989) chama de constrangimentos e limitação ou habilitação e possibilidades sobre as ações (relação com os materiais).

Essa dualidade de conceitos é proposta por Giddens (1989) na teoria da estruturação, constituída como um processo que inclui os elementos da ação - motivação, intencionalidade e racionalidade - e fatores associados aos sistemas sociais institucionais.

Como podemos observar nos excertos seguintes, os professores que ensinam Matemática, de posse de seus conhecimentos, crenças e valores, ao se relacionarem com os materiais curriculares, realizam a análise desses recursos e vislumbram o seu desenvolvimento curricular, a partir das hipóteses sobre o percurso de aprendizagem de seus estudantes. Dessa prática, percebem limitações ao mediar/promover situações de aprendizagem, seja por causa das fragilidades encontradas por eles nos materiais, seja pelo grau de complexidade na apresentação das atividades e no tratamento dos conceitos, ou, ainda, seja pelas dificuldades de seus estudantes. Também percebem possibilidades (affordances) ao identificar que seus objetivos, enquanto docentes, se articulam aos objetivos dos elaboradores dos materiais ou que os modos de apresentação das atividades, tratamento dos conceitos e construção de aprendizagem pelos estudantes vão ao encontro de suas concepções sobre educação.

Na atividade 2, "Organizando a leitura de um número", o grupo destaca a necessidade de mais exemplos para melhor aproveitamento dos alunos. Trabalhar o valor posicional, ordem e classes, e também a localização (Relatório de Pesquisa, fragmento referente ao grupo dos professores do $5^{\circ}$ ano, 2013).

As expectativas propostas estavam adequadas às sequências de atividades, porém havia algumas que apareceram nas sequências e que não estavam previstas na abertura da unidade (Relatório de Pesquisa, fragmento referente ao grupo dos professores do $5^{\circ}$ ano, 2013).

Os professores avaliam que as propostas de atividades do CAA ajudam os alunos a compreenderem os conteúdos de tal forma que as expectativas de aprendizagem sejam atingidas (Relatório de Pesquisa, fragmento referente ao grupo dos professores do $8^{\circ}$ ano, 
2013).

Complementam ainda que as atividades são adequadas porque contemplam de forma objetiva e criativa as expectativas de aprendizagem previstas e abrangem todo o conteúdo necessário para o desenvolvimento das mesmas (Relatório de Pesquisa, fragmento referente ao grupo dos professores do $8^{\circ}$ ano, 2013).

Os professores entendem que as atividades do CAA são adequadas às expectativas de aprendizagem porque colocam os conceitos de forma clara e esclarecedora (Relatório de Pesquisa, fragmento referente ao grupo dos professores do $8^{\circ}$ ano, 2013).

Esses fragmentos ilustram a transferência de autoridade e poder sobre a Matemática e seu ensino. Significam que, no contexto social de situação de aula, ambos os agentes, materiais e professores, têm competências que influenciam e decidem as escolhas curriculares e, como consequência, o que será oportunizado aos estudantes em situações de aprendizagem. A agência, como um fluxo de ação intencional e como capacidade de ação "em uma cadeia de acontecimentos" (GIDDENS, 1979, p. 54) desloca-se entre os agentes, ora presente nos professores, em que estes determinam o currículo, ora nos materiais, em que estes atuam como indutores do currículo.

$\mathrm{Da}$ análise das ponderações dos professores participantes do projeto, presentes no Relatório de Pesquisa, identificamos haver deslocamento de agência dos materiais para os professores quando esses profissionais identificam fragilidades e restrições nos materiais nos modos de apresentar os conteúdos e de tratar os conceitos matemáticos, ou quando não reconhecem suas concepções e princípios nas propostas dos elaboradores. Por outro lado, a agência se desloca dos professores para os materiais quando esses profissionais reconhecem que aquilo que sabem sobre Matemática e seu ensino não é suficiente para eles mesmos elaborarem atividades que atendam às expectativas de aprendizagem dos estudantes e, por isso, exige a busca de recursos que possibilitem tal propósito.

Giddens (1989) nos ajuda a entender que a agência nos professores mune esses profissionais de recursos, levando-os a agir de modos diferenciados para atender aos seus propósitos como responsáveis pelo processo de formação de crianças, adolescentes, jovens, adultos e idosos e configurando-se em uma ação que "implica a possibilidade de poder atuar de outra maneira e, portanto, um 'poder' [...] considerando poder como a capacidade que o ator tem de intervir no curso dos acontecimentos e alterá-los” (p. 10).

\section{Considerações}

Nas situações de aula de Matemática, os professores têm ao seu dispor diferentes 
materiais, ou recursos, que apresentam atividades e tratam de conceitos. Esses profissionais são sujeitos dinâmicos que trazem seus conhecimentos, crenças e valores para as tomadas de decisão sobre que recurso ou parte dele utilizar, bem como para os diferentes modos de interação. Por outro lado, os recursos apresentam características que influenciam nas escolhas dos professores ou determinam procedimentos ao oportunizar atividades aos estudantes. Logo, ambos são sujeitos ativos no desenvolvimento curricular e implicam suas práticas ao mediar/promover situações de aprendizagem.

Dentre os diferentes recursos à disposição dos professores, os materiais curriculares elaborados por Secretarias de Educação, como cadernos de atividades, ou aqueles distribuídos por ações governamentais, como livros didáticos, têm chamado nossa atenção, especificamente a relação entre eles e os professores. Essa relação é determinada por diferentes características presentes nos materiais e por aspectos dos professores, operando como fatores que determinam affordances e agência. Neste artigo, o nosso objetivo foi o de explorar esses conceitos e discutir seus significados na relação professor-materiais curriculares em Educação Matemática.

Como um conceito presente nos materiais, affordance se caracteriza como as possibilidades de ação que esses recursos oportunizam para potencializar os processos de ensino e de aprendizagem. A agência, presente nos materiais e nos professores, traduz o poder de decisão que cada um desses agentes tem sobre o currículo na realização desses processos.

Como oportunidades de ação dos materiais, as affordances são inferidas pelos professores a partir da identificação de informações percebidas por eles ao analisar os recursos. Trata-se de uma inferência do professor sobre o material, e não a de um sujeito externo à relação professor-materiais curriculares.

Assim, da exploração desse conceito e de sua discussão a partir da análise do Relatório de Pesquisa, consideramos ser o conhecimento da Matemática, de questões didáticometodológicas e de aspectos curriculares, aquilo que dá ao professor a capacidade de percepção das informações nos materiais e a exploração, por eles, das affordances. A inferência de affordances é resultado de competências docentes relativas à identificação de informações e propriedades dos materiais curriculares de Matemática.

Nesse sentido, os materiais curriculares significam para os professores o que eles percebem, como produto da interação entre os aspectos físicos dos recursos (informações) e fatores cognitivos (conhecimentos) docentes. A percepção dos professores está relacionada às informações dos materiais. O significado desses recursos para a prática pedagógica refere-se às affordances. Quanto maior o número de informações captadas pelos professores, maior o 
grau de affordance inferida. As informações dos materiais estimulam sensações nos professores e os levam a perceber possibilidades de uso.

Em relação ao Caderno de Apoio e Aprendizagem de Matemática, material usado e avaliado pelos professores participantes do projeto de pesquisa, diferentes informações foram captadas e, do ponto de vista desses profissionais, possibilitaram o desenvolvimento curricular potencializando os processos de ensino e de aprendizagem.

A partir do que teoriza James Gibson, consideramos que as affordances indicam informações (características ou elementos) que um material curricular deve ter para potencializar seu uso e, assim, alcançar o objetivo do sistema educacional: promover a aprendizagem matemática dos estudantes de modo significativo, crítico e emancipador, e engajar os professores no desenvolvimento curricular ajudando-os em suas tomadas de decisão e no fazer pedagógico.

O que destacamos na análise como affordances reflete as possibilidades de ação dos materiais curriculares - Caderno de Apoio e Aprendizagem - inferidas pelos professores participantes do projeto de pesquisa, profissionais que faziam uso desses recursos para mediar/promover situações de aprendizagem. Assim, affordances não podem ser traduzidas como valores atribuídos a esses materiais, mas às possibilidades de ação que potencializam a relação dos docentes com esses recursos e, consequentemente, às experiências em aprender Matemática pelos seus estudantes.

As affordances aqui elencadas, ou outras que possam ser destacadas de demais materiais curriculares, são produto da relação dos professores com esses recursos e de suas inferências. Isso não significa que affordances sejam explicitadas nos materiais, quaisquer que sejam eles, como orientações ao professor ou ao estudante, mas que, dependendo das informações, e de suas qualidades, expressas por esses recursos, diferentes possibilidades de ação poderão ser percebidas por aqueles que fazem uso dos materiais.

A partir do que teoriza Gibson $(1977,1979,1986)$, é importante considerarmos, ainda, que qualquer material curricular tem suas affordances, independentemente de serem inferidas ou não, e que são as informações contidas no recurso que potencializam sua percepção. Disso podemos concluir que, a depender do modo como as informações são apresentadas nos materiais curriculares, incluindo a qualidade delas, pode ser inferido maior ou menor volume de affordances. No entanto, é preciso investir no desenvolvimento profissional docente para que os professores desenvolvam competências e habilidades para, de posse de seus conhecimentos, crenças e valores, perceberem as diferentes possibilidades de ação ao desenvolver o currículo de Matemática. 
As possibilidades de ação que os materiais curriculares oportunizam delimitam as relações entre esses recursos e os professores que ensinam Matemática. As affordances imprimem a agência nos materiais ou seu deslocamento para os professores, atuando como competências que influenciam ou determinam o poder de decisão sobre o currículo.

Como autoridade sobre a Matemática e seu ensino, a agência nos materiais curriculares imprime nesses recursos a característica de ser um recurso potencial, que possibilita ao estudante desenvolver suas competências e habilidades a partir da articulação entre as prescrições, expectativas ou objetivos, e as atividades.

Conceber materiais como agência implica reconhecer que esses recursos traduzem, em situações de aprendizagem, diferentes orientações didático-metodológicas, perspectivas teóricas da Educação e da Educação Matemática e que, principalmente, esses fatores vão ao encontro dos princípios e objetivos dos professores sobre o processo formativo de seus estudantes.

São os professores, como sujeitos ativos da relação com os materiais curriculares, que atribuem ou reconhecem a qualidade de agência, conforme captam informações nesses recursos e percebem affordances. Assim, conforme a inferência de affordances, em termos de quantidade, os materiais se configuram como agência, implicando em ações de reprodução (BROWN, 2002, 2009) ou levando os professores a seguir (REMILLARD, 2005) o que propõem como orientação ou atividades.

Por ter o poder de escolha sobre o currículo, os materiais curriculares, enquanto agência, engajam os professores em uma relação de fidelidade, em que esses profissionais nunca ou raramente intervêm nas atividades ou no modo de abordá-las em sala de aula. A agência nos materiais retira a autonomia dos professores, direcionando-a para esses recursos.

Porém, como todo objeto situado socialmente, os materiais curriculares apresentam restrições e fragilidades, percebidas pelos professores. Esses profissionais adquirem conhecimentos do cotidiano escolar a partir da experiência docente; também possuem conhecimentos, crenças e valores da Matemática, do seu ensino e do processo formativo dos estudantes. Esses elementos revestem os professores de autoridade para agir sobre os materiais e tomar as decisões a partir do que oportunizam como atividades e, desse modo, caracterizam esse profissional como agência.

Os professores, como agência, deslocam a autoridade do material para si e assumem o controle das decisões curriculares. Configura-se, assim, uma relação de adaptação ou improvisação (BROWN, 2002, 2009) ao subverter as propostas de atividades, elaborar outras ou personalizar o desenvolvimento curricular em que se baseiam, interpretam e participam 
com os materiais curriculares (REMILLARD, 2005). A agência nos professores implica, em maior ou menor grau, infidelidade aos materiais curriculares.

Os professores, como agentes, exercem seu poder na tomada de decisão sobre o desenvolvimento curricular a partir da identificação de fragilidades no material: no aspecto de incompletude dos recursos e na percepção de desarticulação entre expectativas (ou objetivos), conteúdos e as demandas formativas dos estudantes.

Como autoridade, e como sujeitos de posse de autonomia, os professores decidem sobre a utilização de outros materiais curriculares ou artefatos pedagógicos, como materiais manipulativos ou recursos tecnológicos; alteram a organização e a seleção dos conteúdos; propõem outras expectativas ou objetivos; elaboram atividades ou alteram aquelas presentes no material; realizam outras abordagens dos aspectos didáticos, metodológicos e conceituais dos conteúdos; personalizam a gestão da aula no que se refere à organização dos tempos e espaços; ampliam ou reduzem as atividades da situação de aprendizagem.

A postura dos professores, ao propor alteração nos materiais, é fundamentada em seus recursos, como discute Brown (2009), quais sejam, conhecimentos do conteúdo, conhecimento pedagógico do conteúdo, e suas crenças e concepções. Trata-se, então, de uma relação com intencionalidade referente aquilo que julgam como certo para promover as aprendizagens matemáticas.

Como sujeitos inseridos em um contexto social, os professores não estão isolados no processo de análise dos materiais e planejamento do desenvolvimento curricular. Seja em espaços institucionalizados, como as reuniões pedagógicas das escolas, seja em situações de formação continuada, os professores trocam suas experiências, socializam suas impressões e captam informações a partir do outro.

Como podemos observar no Relatório de Pesquisa, a participação no projeto e o envolvimento com colegas de diferentes escolas e distintas experiências permitiram aos professores socializar diferentes informações captadas no material curricular comum ao grupo no qual se inseriram. Dessa prática, os professores (re)construíram sentidos e significados sobre os materiais curriculares; perceberam affordances não apreendidas no trabalho individual; e deslocaram a agência para si ou se reconheceram como agência.

$\mathrm{O}$ que queremos afirmar, pela análise que realizamos, é que, embora affordance e agência sejam formulações individuais, o coletivo permite a cada professor e a cada professora o engajamento na percepção de possibilidades de desenvolvimento curricular e a potencialização de competências e habilidades sobre o exercício da autonomia na prática pedagógica. Assim, affordances e agência podem ser competências coletivas. 
Por fim, o que explicitamos aqui não denota juízo de valor sobre materiais curriculares ou sobre os professores. Refere-se a nossa constatação dos modos como esses profissionais se reconhecem como autoridade, atribuem poder aos materiais curriculares e deles percebem possibilidades de uso. No entanto, o que explicitamos traz implicações para a reflexão sobre processos de desenvolvimento profissional docente, envolvendo, principalmente, as noções de formação de professores e políticas públicas para a elaboração e distribuição de materiais curriculares.

\section{Referências}

AHEARN, L. M. Language and agency. Annual Review Antropology, Palo Alto (Califórnia), v. 30, p. 109-137, out. 2001. DOI: 10.1146/annurev.anthro.30.1.109.

BALL, D. L.; COHEN, D. K. Reform by the book: what is - or might be - the role of curriculum materials in teacher tearning and instructional reform? Educational Researcher, Washington, v. 25, n. 9, p. 6-14, dez. 1996. DOI: 10.3102/0013189X025009006.

BARKER, C. Cultural Studies: theory and practice. 3. ed. Londres: Sage, 2008.

BROWN, M. W. Teaching by design: understanding the interaction between teacher practice and the design of curricular innovations. 2002. 543f. Tese (Doutorado em Ciências da Aprendizagem) School of Education \& Social Policy, Northwestern University, Evanston, Illinois (EUA), 2002.

BROWN, M. W. The Teacher-Tool Relationship: theorizing the design and use of curriculum materials. In: REMILLARD, J. T.; HERBEL-EISENMANN, B. A.; LLOYD, G. M. (Ed.). Mathematics Teachers at Work: connecting curriculum materials and classroom instruction. New York: Taylor \& Francis, 2009. p. 17-36.

BROWN, M. W.; EDELSON, D. C. Teaching by Design: curriculum design as a lens on instructional practice. In: ANNUAL MEETING OF AMERICAN EDUCATIONAL RESERCH ASSOCIATION, 2001, Seatle. Anais da AM-AERA: what we know and how we know it. Seatle (Washington): AERA, 2001. p. 1-25.

CHARALAMBOUS, C. Y.; HILL, H. C. Teacher knowledge, curriculum materials, and quality of instruction: unpacking a complex relationship. Journal of Curriculum Studies, v. 44, n. 4, p. 443466, ago. 2012.

COLLOPY, R. Curriculum materials as a professional development tool: how a Mathematics textbook affected two teachers' learning. The Elementary Scholl Journal, Chicago, v. 103, n. 3, p. 287-311, jan. 2003. DOI: 10.1086/499727.

DAVIS, E. A.; KRAJCIK, J. S. Designing educative curriculum materials to promote teacher learning. Educational Researcher, Washington, v. 34, no. 3, p. 3-14, abr. 2005.

DOI: $10.3102 / 0013189$ X034003003.

FIORENTINI, D.; LORENZATO, S. A. Investigaçãa em Educação Matemática: percursos teóricos e metodológicos. 1. ed. Campinas: Autores Associados, 2006.

GIBSON, E. J. Exploratory behavior in the development of perceiving, acting, and the acquiring of knowledge. Annual Review of Psychology, Palo Alto (Califórnia), v. 39, p. 1-41, fev. 1988. DOI: 
10.1146/annurev.ps.39.020188.000245.

GIBSON, E. J.; PICK, A. D. An ecological approach to perceptual learning and development. 1. ed. Oxford, New York: Oxford University Press, 2000.

GIBSON, J. J. A study in the Psychology of decorative art. Unpublished manuscripts. Cornell University, 1979.

GIBSON, J. J. The ecological approach to visual perception. Ed. New Jersey: Lawrence Erlbaum Associates, 1986.

GIBSON, J. J. The senses considered as perceptual systems. 1. ed. Boston: Houghton Mifflin, 1966.

GIBSON, J. J. The theory of affordance. In: SHAW, R.; BRANSFORD, J. (Ed.). Perceiving, acting, and knowing: toward an Ecological Psychology. New Jersey: Lawrence Erlbaum, 1977. p. 67-82.

GIDDENS, A. A constituição da sociedade. Tradução de Álvaro Cabral. 1. ed. São Paulo: Martins Fontes, 1989.

GIDDENS, A. A estrutura de classes das sociedades avançadas. Tradução de Márcia B. de Mello Leite Nunes. 1. ed. Rio de Janeiro: Zahar, 1975.

GIDDENS, A. A política da mudança climática. Tradução de Vera Ribeiro. 1. ed. Rio de Janeiro: Jorge Zahar, 2010.

GIDDENS, A. As consequências da modernidade. Tradução de Raul Fiker. 5. ed. reimpressão. São Paulo: Edunesp, 1991.

GIDDENS, A. Central Problems in social theory: action, structure and condtradiction in social analysis. 1. ed. Berkeley: University of California Press, 1979.

GIDDENS, A. Em defesa da Sociologia: ensaios, interpretações e tréplicas. Tradução de Silvana Vieira e Roneide Venancio Majer. 1. ed. São Paulo: Edunesp, 2001.

GIDDENS, A. New roles of sociological method: a positive critique of interpretative sociologies. 2 . ed. Satanford: Stanford University Press, 1993.

GIDDENS, A. Política, Sociologia e Teoria Social: encontros com o pensamento social clássico e contemporâneo. Tradução de Cibele Saliba Rizek. 1. ed. São Paulo: Edunesp, 1997.

HACKER, P. M. S. Natureza humana: categorias fundamentais. Tradução de José Alexandre Durry Guerzoni. 1. ed. Porto Alegre: Artmed, 2010.

HUNTER, J. E.; SCHMIDT, F. L. Methods of meta-analysis: correcting error and bias in research findings. 3. ed. Thousand Oaks: Sage Publications, 2014.

LIN, H.; FISHMAN, B. Exploring the relationship between teachers' experience with curriculum and their understanding of implicit unit structures. In: INTERNATIONAL CONFERENCE ON LEARNING SCIENCES, 07., 2006, Bloomington (Indiana, USA). Proceedings of ICLS 2006. Bloomington: Indiana University School of Education, National Science Foundation, 2006. p. 432438.

LLOYD, G. M. Two teachers' conceptions of a reform-oriented curriculum: implications for Mathematics teacher development. Journal of Mathematics Teacher Education, v. 2, p. 227-252, 1999. 
MAWYER, K. K. N.; EDELSON, D. C. Beliefes, deciosions and adaptations: a test case study a teacher's participation with investigations. In: ANNUAL INTERNATIONAL CONFERENCE NATIONAL ASSOCIATION FOR RESEARCH IN SCIENCE TEACHING. 2007. Anais da AIC-

NARST: Restructuring Science Education Through Research. New Orleans: NARST, 2007. p. 1-15.

McCLAIN, K. et al. Understanding the Role of the Institutional Context in the Relationship Between Teachers and Text. In: REMILLARD, J. T.; HERBEL-EISENMANN, B. A.; LLOYD, G. M. (Ed.). Mathematics Teachers at Work: connecting curriculum materials and classroom instruction. New York: Taylor \& Francis, 2009. p. 56-69.

MORAES, M. C. Ecologia dos saberes: complexidade, transdisciplinaridade e educação. 1. ed. São Paulo: ProLíbera, 2008.

MOUZELIS, N. P. Modern and postmodern Social Theorizing: bridging the divide. 1. ed. Cambridge: Cambridge University Press, 2008.

PIRES, C. M. C. Relatório de pesquisa. Avaliação de Professores do Ensino Fundamental da Secretaria Municipal de Educação de São Paulo, em relação a documentos e materiais de apoio à organização curricular na área de Educação Matemática. São Paulo: PUC-SP / Unicsul / SME-SP, 2013.

REMILLARD, J. T. Examining key concepts in research on teachers'use of Mathematics Curricula. Review of Educational Research, Washington, American Educational Research Association, v. 75, n. 2, p. 211-246, jun. 2005. DOI: 10.3102/00346543075002211.

REMILLARD, J. T. Modes of engagement: understanding teachers' transactions with Mathematics curriculum resources. In: GUEUDET, G.; PEPIN, B.; TROUCHE, L. (Ed.). From text to lived' resources: Mathematics curriculum materials and teacher development. New York: Springer, 2012. p. 105-122. DOI: 10.1007/978-94-007-1966-8.

REMILLARD, J. T.; GEIST, P. K. Supporting teachers' professional learning by navigating openings in the curriculum. Journal of Mathematics Teacher Education, v. 5, p. 7-34, 1999.

SANTIN, T. R. Concepções e perspectivas de agência epistêmica. 2015. 133f. Dissertação (Mestrado em Filosofia) - Faculdade de Filosofia e Ciências Humanas, Pontifícia Universidade Católica do Rio Grande do Sul, Porto Alegre, 2015.

SCHNEIDER, R. M. Opportunities for teacher learning during enactment of Inquiry Science Curriculum Materials: exploring the potential for teacher educative materials. Journal of Science Teacher Education. v. 24, n. 2, p. 323-346, mar. 2012. DOI: 10.1007/s10972-012-9309-9.

SCHNEIDER, R. M.; KRAJCIK, J. Supporting science teacher learning: the role of educative curriculum materials. Journal of Science Teacher Education. v. 13, n. 3, p. 221-245, ago. 2002. DOI: 10.1023/A:1016569117024.

SEWELL JR., W. H. A theory of structure: duality, agency, and transformation. American Journal of Sociology, Chicago, v. 98, n. 1, p. 1-29, jul. 1992. DOI: 10.1086/229967.

STEIN, M. K.; KIM, G. The role of Mathematics curriculum materials in large-scale urban reform: an analysis of demands and opportunities for teacher learning. In: REMILLARD, J. T; HERBELEISENMANN, B. A.; LLOYD, G. M. (Ed.). Mathematics Teachers at Work: connecting curriculum materials and classroom instruction. New York: Taylor \& Francis, 2009. p. 37-55.

STONES, R. Ação e agência. In: SCOTT, J. (Org.). Sociologia: conceitos-chave. Tradução de Carlos Alberto Medeiros. 1. ed. Rio de Janeiro: Zahar, 2010. p. 13-17. 
WANG, J.; PAINE, L. W. Learning to teach with mandated curriculum and public examination of teaching as contexts. Teaching and Teacher Education. v. 19, n. 1, 75-94, jan. 2003. DOI: 10.1016/S0742-051X(02)00087-2.

Submetido em 03 de Maio de 2017. Aprovado em 02 de Outubro de 2017. 